\title{
THERMAL STABILITY OF Ag-EXCHANGED CLINOPTILOLITE RICH MINERAL
}

\author{
Y. Akdeniz ${ }^{*}$ and S. $\ddot{U} l k \ddot{u}$ \\ Chemical Engineering Department, Faculty of Engineering, Izmir Institute of Technology, Gülbahçe Köyü 35437-Urla, Izmir, Turkey
}

Thermal stability of clinoptilolite rich mineral from Western Anatolia, Turkey and its Ag-exchange forms was investigated. Parent mineral of different sizes were heated up to $1000^{\circ} \mathrm{C}$ with heating rate of 2 and $10^{\circ} \mathrm{C} \mathrm{min}^{-1}$ using differential thermal analyzer (DTA) and thermogravimetric analyzer (TG). Ag exchange was conducted both in conventional constant temperature waterbath and microwave at 40,60 and $80^{\circ} \mathrm{C}$. The exchanged minerals were then characteized by scanning electron microscopy (SEM), X-ray diffractometry (XRD), Fourier transform infrared spectroscopy (FTIR), DTA and TG.

The particle size and heating rate do not have significant effect on the thermal behavior of the parent mineral and no structural changes were observed with $\mathrm{Ag}$ exchange, only decomposition temperature was lowered. It was finally concluded that, Ag-exchanged clinoptilolite rich minerals were less thermally stable compared to parent mineral that does not affect their use for possible applications.

Keywords: Ag-clinoptilolite, heating rate, microwave, particle size, thermal stability

\section{Introduction}

Natural zeolites are formed mostly from the reaction of pore waters with volcanic glass and also by alteration of pre-existing feldspars, feldspathoids, poorly crystalline clay and biogenic silica. More than 50 different species of natural zeolites are known today but among them clinoptilolite is the most widespread one found in nature with high purity. It is available in many regions of Turkey for example; Balıkesir, Bigadiç; Emet, Yukarıağaç; Izmir, Urla; Manisa, Gördes, Kıranköy, Avdaldere regions are available as sedimentary clinoptilolite and analcime deposits [1]. Natural zeolites have special value due to their characteristic properties, such as adsorption, catalytic and ion exchange property. These properties are enhanced in the dehydrated/calcined state thus the understanding of their behavior upon heating is important.

Clinoptilolite, silica rich zeolite, is a member of heulandite group of natural zeolites. Clinoptilolite and heulandite are differing from each other with respect to their thermal stability, $\mathrm{Si} / \mathrm{Al}$ ratio and preferential presence of $\mathrm{Na}^{+}$and $\mathrm{K}^{+}$in the exchangeable sites [2]. Clinoptilolite has $\mathrm{Si} / \mathrm{Al}>4$ and it survives its crystal structure an overnight heating at $450^{\circ} \mathrm{C}$, while heulandite has $\mathrm{Si} / \mathrm{Al}<4$ and undergoes structural collapse below $450^{\circ} \mathrm{C}$ [3]. Thermal analyses techniques such as; thermogravimetric analysis (TG), differential thermal analysis (DTA), are used in order to differentiate clinoptilolite and heulandite, which are also good and straightforward methods used to determine the thermal stability of the minerals. Clinoptilolite structure consists of a two-dimensional system of the three types of channels. Two parallel channels, channel A (10 member ring) and channel B (8 member ring) which are perpendicularly intersected by channel $\mathrm{C}$ ( 8 member ring) with sizes 4.4.7.2, 4.1.4.7 and 4.0.5.4 $\AA$, respectively. The channels were filled with water and exchangeable cations, mainly $\mathrm{Na}, \mathrm{Ca}, \mathrm{K}, \mathrm{Mg}$ and $\mathrm{Ba}$. These exchangeable cations are located in the main sites of clinoptilolite coordinated with different number of water molecules and oxygen atom. Framework Si/Al ratio, ionic potential, size and composition of exchangeable cations, their coordination after water expulsion and framework topology are some of the factors which affect thermal behavior of zeolites. Cruciani (2006) stated that, as $\mathrm{Si} / \mathrm{Al}$ ratio increases thermal stability will also increase because energy is required to break the $\mathrm{Si}-\mathrm{O}$ bond compared to the Al-O bond is high. Thermal stability of zeolites are also described in terms $\mathrm{Si} /(\mathrm{Si}+\mathrm{Al})$ ratio. Zeolites with high silica content having $\mathrm{Si} /(\mathrm{Si}+\mathrm{Al})$ ratio higher than $0.79(\mathrm{Si} / \mathrm{Al} \geq 3.80)$ and zeolites with low silica having $\mathrm{Si} /(\mathrm{Si}+\mathrm{Al})$ ratio lower than $0.56(\mathrm{Si} / \mathrm{Al} \leq 1.28)$ exhibit a large and poor thermal stability, respectively. The water-cation, water-water and water-oxygen atom interactions are differ from the zeolites having different cation content. In addition to that, zeolites

\footnotetext{
* Author for correspondence: yeldaakdeniz@iyte.edu.tr
} 
containing monovalent alkali cations (e.g. $\mathrm{K}^{+}, \mathrm{Na}^{+}$) are said to be more stable than those containing divalent cations (e.g. $\mathrm{Ca}^{2+}$ ). Larger cations (e.g. $\mathrm{K}^{+}$) prevent the zeolite structure from collapse while smaller cations (e.g. $\mathrm{Na}^{+}, \mathrm{Ca}^{2+}$ ) do not. This is due to the fact that bigger cations keep the rings open while smaller ones are very small that they cannot maintain expansion of the channels [4]. Concepcion et al., 2005, had studied the thermal behavior of Ag-exchanged natural and synthetic zeolites and they concluded that Ag-natural clinoptilolite samples were less thermally stable [5].

Depending on the composition of the exchangeable cations, TG and DTA curves of the zeolitic minerals show different characteristics. According to Breck [6] no steps and discontinuities were shown on typical TG curve of clinoptilolite regarding no structural changes upon dehydration. The difference in starting and ending temperatures of endothermic and exothermic peaks of zeolites on DTA curves also results due to different cation content of the minerals. In the dehydration process of clinoptilolite, the endothermic effect is observed in the temperature range of 20 to $700^{\circ} \mathrm{C}$, where first least bonded water then the water with higher energy of bonds is removed. The exothermic effect at about $550^{\circ} \mathrm{C}$ is related to the phase transformation and/or crystallization of the amorphous phase [7]. Esenli and Kumbasar, 1994 had studied the thermal behavior of clinoptilolite samples from Western Anatolia. They concluded, the cationic ratios, positions had an effect on the decomposition and/or phase transition temperature of clinoptilolite [8].

The development of new clean-up technologies is still a need since the current methods have many limitations. Natural zeolites and their modified forms were used for this purpose since they have adsorption and ion exchange property. Chmielewská et al., 2008, modified the Slovakian natural clinoptilolite with surfactant octadecylammonium and alginate biopolymers and determined their thermal resistance in respect to the original mineral by thermal analyses (TG/DTA) in the temperature range $30-1000^{\circ} \mathrm{C}$. The native clinoptilolite indicated broad endotherm around $100-130^{\circ} \mathrm{C}$, resulted from the loss of adsorbed water while ODA-modified clinoptilolite had additional broad exotherm at 370 up to $560^{\circ} \mathrm{C}$. This DTA profile is assumed to record a slowly breakdown of attached ODA surfactant and sequential mass loss due to continual heating of sample under elevated temperature. They concluded that ODA surfactant modified Slovakian natural clinoptilolite is less thermally stable compared to parent mineral [9].

As mentioned earlier, most zeolites are dehydrated to some degree without major alteration of their crystal structure. However in some zeolites irreversible changes in the framework structure occurs after complete dehydration; exchangeable cations initially located in the channels, may then become captured within the structure [5]. Vujaković et al., 2001, had studied the surfactant and anion adsorption of clinoptilolite. Different forms of clinoptilolite $\left(\mathrm{Ca}^{2+}, \mathrm{Na}^{+}, \mathrm{Ca}^{2+} / \mathrm{H}^{+}\right.$and $\left.\mathrm{H}^{+}\right)$and surface modified clinoptilolite (SCM) were studied. SMC is greatly influenced by cationic and structural form of clinoptilolite and metal forms did not go under structural deformation with heating upto $700^{\circ} \mathrm{C}$ [10]. Misshra, 2004, had been studied the structural and thermal stability of zeolite-13X and its $\mathrm{Mn}$ (II) and $\mathrm{Zn}$ (II) exchange forms up to $900^{\circ} \mathrm{C}$ and concluded that a little change in d-spacing occurred and peak intensities were reduced after exchange with $\mathrm{Mn}$ (II) and $\mathrm{Zn}$ (II) ions but the structure remained crystalline. Vujaković et al., 2001, had studied the surfactant and anion adsorption of clinoptilolite. They worked with different forms of clinoptilolite $\left(\mathrm{Ca}^{2+}, \mathrm{Na}^{+}, \mathrm{Ca}^{2+} / \mathrm{H}^{+}\right.$ and $\mathrm{H}^{+}$) and surface modified clinoptilolite (SCM) and found that SMC is greatly influenced by cationic and structural form of clinoptilolite and metal forms did not go under structural deformation with heating up to $700^{\circ} \mathrm{C}$ [11]. Afzal et al., 2000, had studied on the thermal behavior of $\mathrm{Co}^{2+}, \mathrm{Cu}^{2+}$ and $\mathrm{Ni}^{2+}$ exchanged zeolite 4A. They concluded that the mass loss for the metal-exchanged zeolite was greater than that for the pure zeolite. The DTA maximum peak for the pure zeolite was observed at $125^{\circ} \mathrm{C}$, while for the metal-exchanged zeolite (except for $\mathrm{Cu}$ ) the main peak was shifted towards lower temperature and as the metal concentration was increased, the water content also increased [12, 13].

Thermodynamic information of hydration processes of zeolites is also very important for utilizing the zeolites as heat exchangers. On this purpose, many studies have been done and final conclusion of all researches is that the nature of the dehydration/ hydration process of zeolites is controlled by the hydration energy of extra-framework cations and structural variation during dehydration. Petrova et al., 2001, made calorimetric measurements for water absorption to determine the integral molar enthalpy of hydration on purified clinoptilolite, and $\mathrm{K}, \mathrm{Na}, \mathrm{Ca}$ and $\mathrm{Mg}$-exchanged clinoptilolite for evaluating zeolites as heat exchangers and concluded that natural zeolites can be used for this purpose [14].

XRD analysis combined with the thermal analysis is important in order to obtain complete picture of crystallographic transformations upon heating. On XRD patterns, characteristics XRD lines of the clinoptilolite rich mineral are observed at 9.92, 22.43 and $30.50^{\circ} 2 \theta$ [15]. Çağlar et al. 2006, had 
studied thermal behavior of zeolitic tuff from Gördes-Manisa in the temperature range of $200-1200^{\circ} \mathrm{C}$. They have concluded that, heating the tuff up to $600^{\circ} \mathrm{C}$ did not cause any structural change detectable by X-ray powder diffraction and thermal characterization methods with regard to the original sample, while further increase in the temperature caused structural breakdown of zeolitic tuff [16]. Erdoğan et al., 2008, had studied the efficiency of Turkey clinoptilolite-rich tuff from Gördes and Bigadiç region of western of Anatolia and their exchanged forms $\left(\mathrm{K}^{+}, \mathrm{Na}^{+}\right.$and $\left.\mathrm{Ca}^{2+}\right)$ in the removal of ethylene. They started with characterizing the parent and modified minerals. The XRD patterns of parent and modified minerals showed that no significant structural changes occurred within the structure whereas the existence of various exchangeable cations in zeolites leads to changes in temperature of zeolitic water elimination. The zeolite water loss is higher in the zeolites exchanged with bivalent ion. In addition, in the monovalent ions, the larger cations have less zeolite water [17].

FTIR spectra of clinoptilolite are divided into two classes. The first class of vibrations arises due to internal vibrations of the $\mathrm{TO}_{4}$ tetrahedron are called asymmetry stretch $\mathrm{O}-\mathrm{Si}(\mathrm{Al})-\mathrm{O}$, symmetry stretch and $\mathrm{T}-\mathrm{O}$ double ring which are observed at 1250-950, 750-650, 500-420 $\mathrm{cm}^{-1}$ wavelengths, respectively. The second class of vibrations; $\mathrm{T}-\mathrm{O}$ double ring, pore opening, symmetry stretch, asymmetry stretch related to the linkages between the tetrahedral are observed at 650-500, 420-300, 750-820, 1150-1050 $\mathrm{cm}^{-1}$ wavelength, respectively. Additionally, $\mathrm{H}$ bonded $\mathrm{H}_{2} \mathrm{O}, \mathrm{H}-\mathrm{O}$ and isolated $\mathrm{OH}$ stretching are at 3400 and $3700 \mathrm{~cm}^{-1}$ wavelengths, respectively $[5,13]$. Ion exchange process causes formation of new bond and structure of zeolites which can change due which could be detected by FTIR [18].

Ag-clinoptilolite is a potential mineral for antimicrobial material production such as antimicrobial ceramics and antibacterial materials for medical applications. Besides, the wide abundance of clinoptilolite in Turkey created an economical potential for the country. In that respect, determination of thermal behavior of Ag-clinoptilolite has a special value for possible applications. The aim of this study is to determine thermal stability of Ag-exchanged clinoptilolite rich mineral from Western Anatolia, Turkey. The effect of particle size and heating rate on the thermal behavior of the mineral was also investigated.
Table 1 Particle size ranges of clinoptilolite rich mineral

\begin{tabular}{c}
\hline Particle size range \\
\hline $1.7 \mathrm{~mm}-425 \mu \mathrm{m}$ \\
$425-106 \mu \mathrm{m}$ \\
$106-25 \mu \mathrm{m}$ \\
$25 \mu \mathrm{m}-$ ultrafine \\
\hline
\end{tabular}

Table 2 Chemical composition of clinoptilolite rich mineral

\begin{tabular}{lc}
\hline Elements & Mass $/$ mass $\%$ \\
\hline $\mathrm{SiO}_{2}$ & 69.89 \\
$\mathrm{Al}_{2} \mathrm{O}_{3}$ & 11.21 \\
$\mathrm{Fe}_{2} \mathrm{O}_{3}$ & 1.15 \\
$\mathrm{~K}_{2} \mathrm{O}$ & 5.48 \\
$\mathrm{CaO}$ & 1.89 \\
$\mathrm{Na}_{2} \mathrm{O}$ & 1.56 \\
$\mathrm{MgO}$ & 0.22 \\
\hline
\end{tabular}

\section{Experimental}

\section{Materials and methods}

Clinoptilolite rich mineral, obtained from western part of Anatolia were used throughout the experimental study, which is divided into three parts. In the first part, the effect of particle size and heating rate on the thermal behavior of the parent mineral was determined. Mineral was first crushed into smaller particles in FRITSCH jaw crusher and sieved into different particle size ranges. Then, they were wet sieved in each particle size range in order to remove soluble impurities and dried overnight at $65^{\circ} \mathrm{C}$. The dried mineral was kept at constant relative humidity in order to obtain same condition before the analyses. Thermal Analysis of the minerals was performed using Shimadzu TGA-51 and Shimadzu DTA-50 in the range of room temperature to $1000^{\circ} \mathrm{C}$ for $\mathrm{TG}$ and DTA analysis, respectively at two heating rates of 2 and $10^{\circ} \mathrm{C} \mathrm{min}{ }^{-1}$ under $40 \mathrm{~mL} \mathrm{~min}^{-1} \mathrm{~N}_{2}$ atmosphere. The particle size ranges obtained are given in Table 1 .

In the second part of the experimental study, $\mathrm{Ag}$ exchange was conducted using 150-250 $\mu \mathrm{m}$ particle sized minerals. The chemical composition of the clinoptilolite rich mineral was determined by inductively coupled plasma atomic emission spectroscopy; Varian (ICP-AES) using borate fusion method. The results are tabulated in Table 2.

The parent mineral having $\mathrm{Si} / \mathrm{Al}$ ratio of 6.23 was defined as K-rich mineral. The trace elements amounts (ppm) were found as; $\mathrm{Cu}^{2+}(14.89), \mathrm{Li}^{+}(<2)$, 

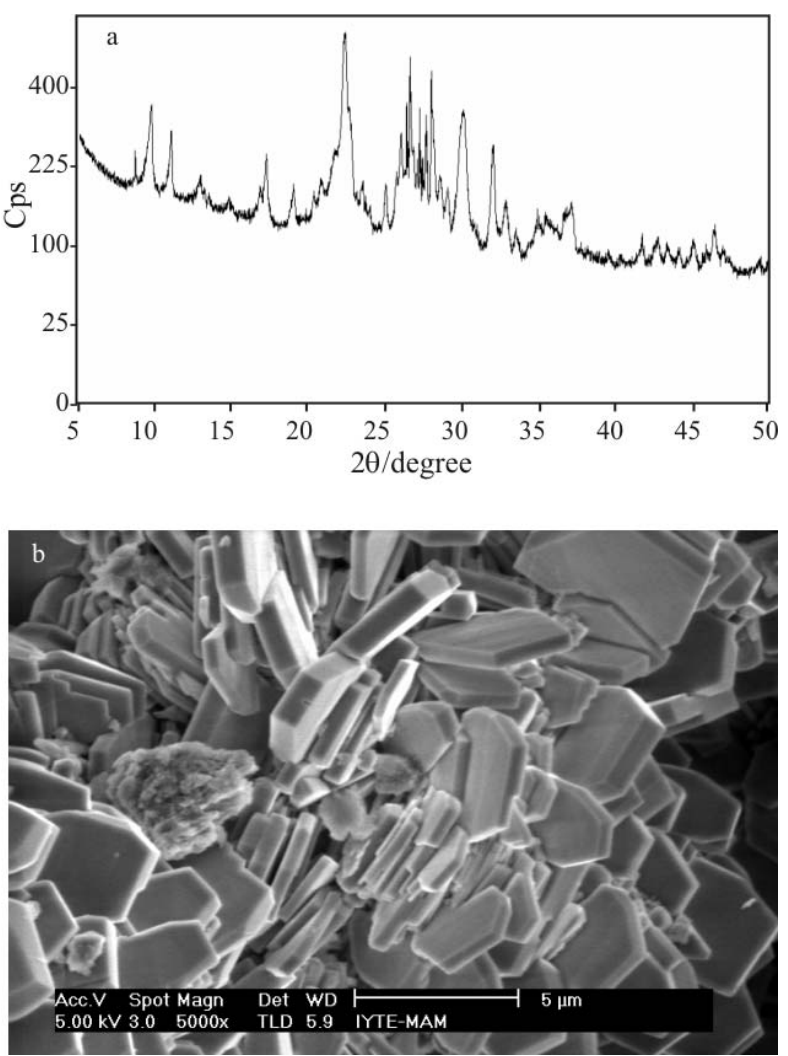

Fig. 1 Clinoptilolite rich mineral a - XRD pattern, b - SEM

$\mathrm{Co}^{3+}(6.45), \quad \mathrm{Cr}^{3+}(6.98), \quad \mathrm{Ni}^{2+}(<4), \quad \mathrm{Pb}^{2+}(48.72)$, $\mathrm{Ag}^{+}(3.19)$ and $\mathrm{Zn}^{2+}(60.12)$.

X-ray powder diffraction (XRD) measurement of the parent mineral was carried out using Philips $\mathrm{X} /$ Pert X-ray diffractometer with $\mathrm{Ni}$ filtered $\mathrm{CuK}_{\alpha}$ radiation in the range of $2 \theta$ values 5 to $40^{\circ}$. Additionally, scanning electron micrograph (SEM) of the parent mineral was taken by using Philips XL 30S FEG. The XRD pattern and SEM of the parent mineral were given in Fig. 1.

The mineral was mainly clinoptilolite showing the characteristic peaks outlined by Arcoya et al. 1999 , at $9.92,22.43,26.8$ and $30.50^{\circ} 2 \theta$ values. The mineral peaks overlapped with the ones given by the JSPDS 83-1261 card belonging to clinoptilolite having some extra peaks corresponding to heulandite (JSPDS card 80-0465) and additionally, calcite, quartz and mordenite, were present within the mineral determined by search match software program attached to XRD. The typical clinoptilolite crystals were clearly seen on the parent mineral SEM, as well.

In the third and final part of the experimental study, the Ag exchanged clinoptilolite rich minerals were prepared and their thermal stability was investigated. Prior to Ag-exchange, near homoionic form clinoptilolite rich mineral were formed as follows; $125 \mathrm{~g}$ of parent mineral $(150-250 \mu \mathrm{m})$ was treated with $1250 \mathrm{~mL}$ of $1 \mathrm{~N} \mathrm{NaCl}$ solution in a constant temperature water bath maintained at $80^{\circ} \mathrm{C}$ for one week. $\mathrm{NaCl}$ solution was replaced in every three days. Then, Na-clinoptilolite $(\mathrm{S} / \mathrm{L}=1 / 100)$ put in $0.01 \mathrm{M} \mathrm{AgNO}_{3}$ solution for $1 \mathrm{~h}$ in microwave and for $24 \mathrm{~h}$ in waterbath. The microwave exchange was conducted using Mars 5-CEM, digestion and extraction equipment. The commercial exchange will be conducted using constant temperature waterbath, GLC Model-1084. The exchanges were conducted at three temperatures, 40,60 and $80^{\circ} \mathrm{C}$. Ag exchanged clinoptilolite rich minerals were washed with deionized water several times after completion of the exchange, dried overnight at $65^{\circ} \mathrm{C}$ and kept at constant relative humidity. Infrared spectra of all the samples were taken by using Fourier transform infrared spectrophotometer, Shimadzu (FTIR-8201) using $\mathrm{KBr}$ pellet techniques. Typical pellet contains 1-2 mass\% samples in $\mathrm{KBr}$. The amount of zeolite in the $\mathrm{KBr}$ pellet was chosen so to provide the linear dependence of optical density of characteristic IR bands vs. zeolite content.

Table 3 Total $\%$ of water loss up to $1000^{\circ} \mathrm{C}$ with different heating rates

\begin{tabular}{lcrc}
\hline Size range & \multicolumn{2}{c}{ Average } \\
\hline \multicolumn{3}{c}{$2{ }^{\circ} \mathrm{C} \mathrm{min}^{-1}$} \\
$1.7 \mathrm{~mm}-425 \mu \mathrm{m}$ & 8.7 & 10.4 & 9.5 \\
$425-106 \mu \mathrm{m}$ & 10.9 & 8.7 & 9.8 \\
$106-25 \mu \mathrm{m}$ & 8.9 & 8.4 & 8.6 \\
$25 \mu \mathrm{m}-$ ultrafine & 9.8 & 7.5 & 8.7 \\
\hline \multicolumn{4}{c}{$10^{\circ} \mathrm{C} \mathrm{min}^{-1}$} \\
$1.7 \mathrm{~mm}-425 \mu \mathrm{m}$ & 9.7 & 8.8 & 9.3 \\
$425-106 \mu \mathrm{m}$ & 8.4 & 8.1 & 8.9 \\
$106-25 \mu \mathrm{m}$ & 8.7 & 8.9 & 8.8 \\
$25 \mu \mathrm{m}-$ ultrafine & 10.4 & - & 10.4 \\
\hline
\end{tabular}

Table 4 Dehydration behavior (DTA) of clinoptilolite rich mineral

\begin{tabular}{lcccc}
\hline \multirow{2}{*}{ Size range } & \multicolumn{2}{c}{$2{ }^{\circ} \mathrm{C} \min ^{-1}$} & \multicolumn{2}{c}{$10^{\circ} \mathrm{C} \mathrm{min}^{-1}$} \\
\cline { 2 - 5 } & Endothermic peak $/{ }^{\circ} \mathrm{C}$ & Exothermic peak $/{ }^{\circ} \mathrm{C}$ & Endothermic peak $/{ }^{\circ} \mathrm{C}$ & Exothermic peak $/{ }^{\circ} \mathrm{C}$ \\
\hline $1.7 \mathrm{~mm}-425 \mu \mathrm{m}$ & 48.4 & 914.2 & 51.5 & 868.3 \\
$425-106 \mu \mathrm{m}$ & 47.3 & 971.7 & 48.1 & 949.9 \\
$106-25 \mu \mathrm{m}$ & 48.1 & 920.8 & 51.7 & 925.0 \\
$25 \mu \mathrm{m}$-ultrafine & 47.2 & 929.9 & 51.5 & 966.2 \\
\hline
\end{tabular}




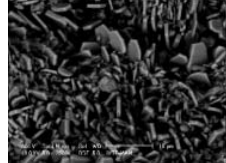

a- $40^{\circ} \mathrm{C}$

b- $40^{\circ} \mathrm{C}$

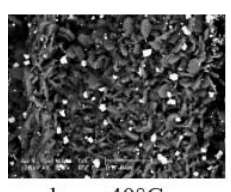

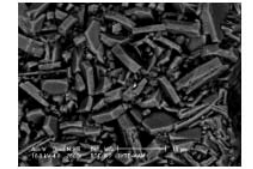

$60^{\circ} \mathrm{C}$

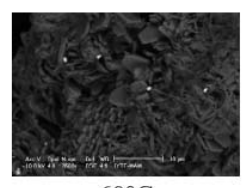

$60^{\circ} \mathrm{C}$

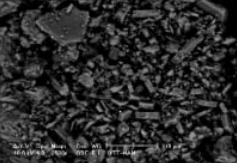

$80^{\circ} \mathrm{C}$

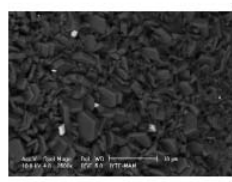

$80^{\circ} \mathrm{C}$
Fig. 2 SEM of the Ag-exchanged minerals exchanged in $\mathrm{a}$ - waterbath, $\mathrm{b}$ - microwave

\section{Results and discussion}

Thermal behavior of clinoptilolite rich mineral at different particle size ranges determined using TG and DTA are summarized in Tables 3 and 4, respectively.

Total mass loss $\%$ of the clinoptilolite rich mineral for the entire particle size ranges at both heating rates were quite close to each other, which were around $9.13 \%$ indicating that particle size and the heating rate did not affect the dehydration behavior of the minerals.

DTA patterns of the minerals showed low temperature endotherm around $50.70^{\circ} \mathrm{C}$ for the entire particle size ranges at both heating rates indicating the release of their external water. They started to lose their original crystalline structures around $912^{\circ} \mathrm{C}$ which might be due to the conversion of the structure into another crystal or amorphous phase. It can be concluded that particle size and heating rate do not have significant effect on the decomposition temperature of the mineral.

The SEM of Ag-exchanged clinoptilolite minerals at three temperatures are given in Figs 2a and $\mathrm{b}$ for waterbath and microwave exchange, respectively.

Rivera-Garza et al., 2000, had studied the antibacterial activity of Ag-exchanged Mexican zeolite. They observed some small white particles on the surface of the zeolitic material, analyzed them and concluded that they have high concentration of
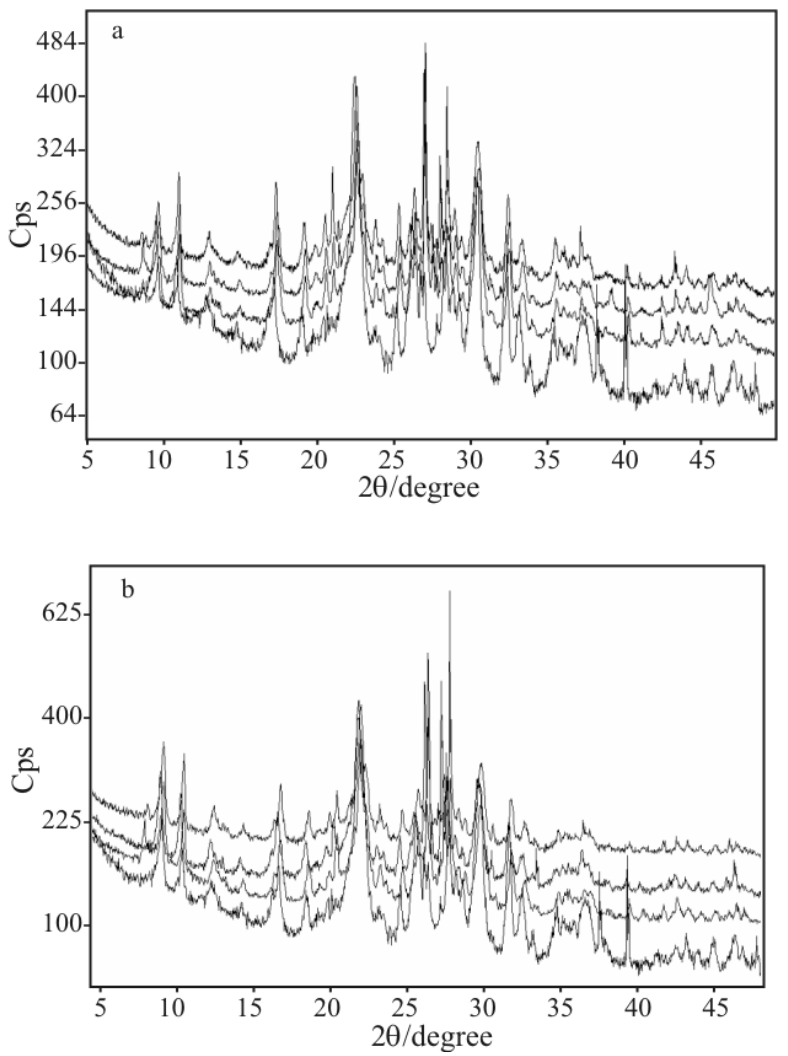

Fig. 3 XRD pattern of the Ag-exchanged minerals in comparison with $\mathrm{Na}$-form mineral exchanged in $\mathrm{a}$ - waterbath, $\mathrm{b}$ - microwave (top to bottom: 80,60 and $40^{\circ} \mathrm{C}$ of exchange and $\mathrm{Na}$-form clinoptilolite rich mineral)

Table 5 Chemical composition Na-form and Ag-exchanged clinoptilolite rich mineral

\begin{tabular}{lcrrrrrr}
\hline \multirow{2}{*}{ Elements } & \multirow{2}{*}{$\begin{array}{c}\text { Na-form } \\
\text { mineral }\end{array}$} & \multicolumn{3}{c}{ Waterbath treatment $/ 24 \mathrm{~h}$} & \multicolumn{3}{c}{ Microwave treatment/1 h } \\
\cline { 3 - 8 } & 11.54 & 11.01 & 10.99 & 10.73 & 11.49 & 11.63 & 11.90 \\
\hline $\mathrm{Al}_{2} \mathrm{O}_{3}$ & 69.14 & 63.44 & 65.65 & 66.89 & 67.05 & 67.48 & 70.46 \\
$\mathrm{SiO}_{2}$ & 0.88 & 0.42 & 0.36 & 0.33 & 0.34 & 0.28 & 0.43 \\
$\mathrm{CaO}^{\circ}$ & 1.16 & 1.14 & 1.47 & 1.21 & 1.03 & 0.92 & 1.27 \\
$\mathrm{Fe}_{2} \mathrm{O}_{3}$ & 3.92 & 3.85 & 3.59 & 3.92 & 3.27 & 2.20 & 3.67 \\
$\mathrm{~K}_{2} \mathrm{O}$ & 0.18 & 0.17 & 0.02 & 0.15 & 0.13 & 0.13 & 0.17 \\
$\mathrm{MgO}$ & 5.61 & 2.41 & 1.86 & 2.39 & 2.71 & 1.69 & 2.75 \\
$\mathrm{Na} 2 \mathrm{O}$ & 0.00 & 11.08 & 11.18 & 11.27 & 3.84 & 2.94 & 4.56 \\
$\mathrm{AgO}$ & 5.99 & 5.76 & 5.97 & 6.23 & 5.84 & 5.80 & 5.92 \\
$\mathrm{Si} / \mathrm{Al}$ & 0.86 & 0.85 & 0.86 & 0.86 & 0.85 & 0.85 & 0.86 \\
$\mathrm{Si} /(\mathrm{Si}+\mathrm{Al})$ & & & & & & & \\
\hline
\end{tabular}


silver [19]. In the above micrographs similar white particles were observed and agreed that they are corresponding to $\mathrm{Ag}^{+}$ions. Their distributions on the micrographs were not the equal but minerals have almost the same Ag compositions for individual exchange, which is concluded from the ICP results tabulated in Table 5. This could be explained by the fact that; after the exchange, the minerals were washed several times and during washing $\mathrm{Ag}^{+}$ particles on the surface of the minerals might sweep away. Additionally, compared to SEM of the parent mineral, the $\mathrm{Ag}^{+}$exchanged minerals did not show any structural changes with exchange process since the characteristic clinoptilolite crystals are clearly seen on Figs $2 a$ and $b$.

XRD patterns of the Ag-form clinoptilolite rich mineral at different temperatures of waterbath and microwave exchange in comparison with $\mathrm{Na}$-form of the mineral are given in Figs $3 a$ and b, respectively.

The inspection of XRD patterns confirms that no transition of clinoptilolite and heulandite phase occurred during the exchanges conducted both in waterbath and microwave. The decrease in peak intensity at $9.92^{\circ} 2 \theta$ for the Ag exchange minerals is due to differences in their chemical compositions. Additional peaks corresponding to Ag particles were not observed on their XRD patterns since Ag particles are quite small that are not detected by XRD.

The chemical compositions of the waterbath and microwave exchanged minerals are given in Table 5 .

As it is indicated in Table 5, after the exchange with $\mathrm{Ag}^{+}$no considerable changes were observed for the major cations except $\mathrm{Ca}^{2+}$ and $\mathrm{Na}^{+}$. The higher exchange amounts of these cations could be explained by the structural location of $\mathrm{Na}^{+}$and $\mathrm{Ca}^{2+}$ within the mineral. The difference in the hydration spheres associated with each other also leads higher exchange of $\mathrm{Na}^{+}$. Additionally, hydrated ionic radii of the cations affect the exchange degree. Nearly the same size of the hydrated radii of the ions as the channel dimensions results difficulty in exchange. The hydrated radius of some cations are follows; $\mathrm{Na}^{+}(3.58 \AA)$, $\mathrm{K}^{+}(3.31 \AA), \quad \mathrm{Mg}^{2+}(4.28 \quad \AA), \quad \mathrm{Ca}^{2+}(4.12 \AA)$, $\mathrm{Fe}^{3+}(4.28 \AA), \operatorname{Ag}^{+}(3.43 \AA)$. This fact explains why $\mathrm{Ca}^{2+}, \mathrm{Mg}^{2+}$ and $\mathrm{Fe}^{3+}$ cannot move easily out of the channels without removal of their associated water molecules [20].
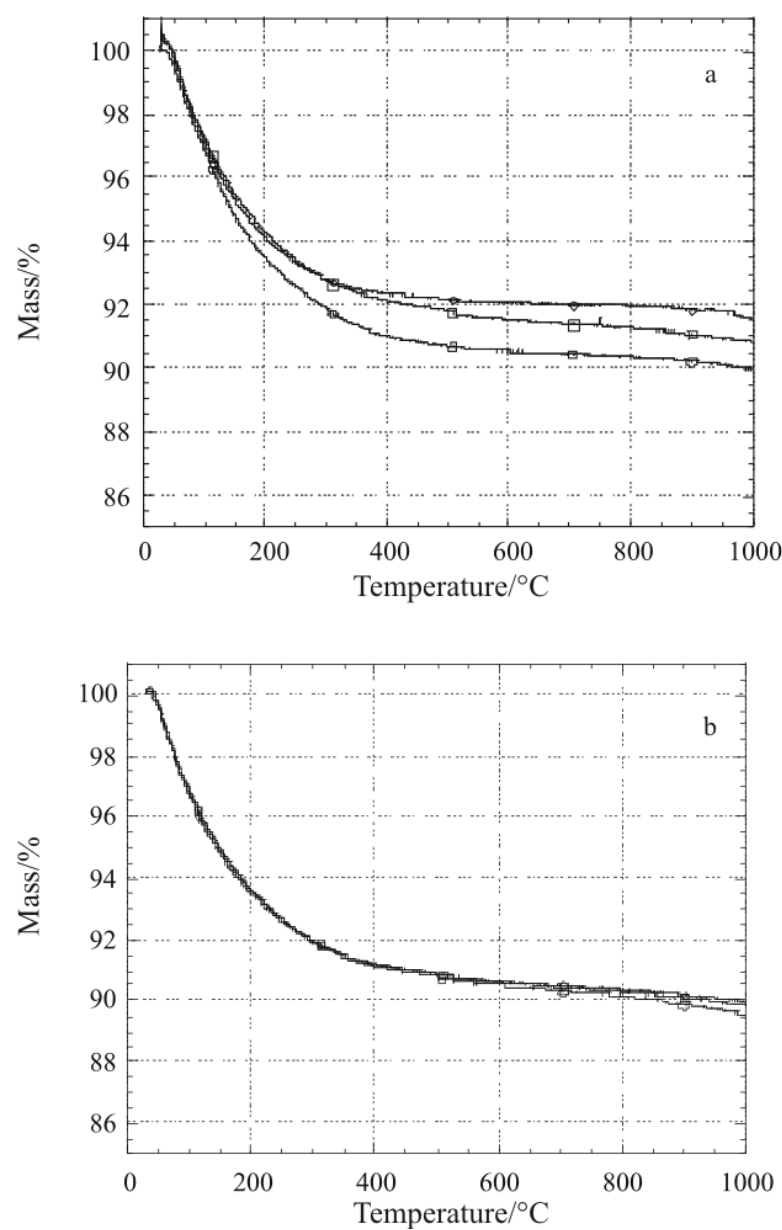

Fig. 4 TG of the Ag-exchanged minerals exchanged in $\mathrm{a}$ - waterbath, $\mathrm{b}$ - microwave (top to bottom: 80,60 and $40^{\circ} \mathrm{C}$ of exchange)

The $\mathrm{Ag}$ exchanged minerals have $\mathrm{Si} / \mathrm{Al}$ ratio higher than 3.80 and $\mathrm{Si} /(\mathrm{Si}+\mathrm{Al})$ ratio higher than 0.79 at three temperatures of waterbath and microwave exchange as indicated in Table 5. Additionally, they have higher $\mathrm{K}^{+}$and $\mathrm{Na}^{+}$(monovalent cation) content compared to $\mathrm{Ca}^{2+}$ (divalent cation) content which are indicating their high thermal stability [4].

TG patterns of the Ag-exchanged clinoptilolite rich mineral at different temperatures of waterbath and microwave exchange in comparison with $\mathrm{Na}$-form of the mineral are given in Figs $4 \mathrm{a}$ and $\mathrm{b}$, respectively which their percent mass losses are summarized in Table 6.

Table 6 Dehydration behavior (DTA) of Ag-exchanged clinoptilolite rich mineral

\begin{tabular}{lcccccc}
\hline & \multicolumn{2}{c}{$40^{\circ} \mathrm{C}$} & \multicolumn{2}{c}{$60^{\circ} \mathrm{C}$} & \multicolumn{2}{c}{$\mathrm{C}$} \\
\cline { 2 - 7 } Method & $\begin{array}{c}\text { Endothermic } \\
\text { peak } /{ }^{\circ} \mathrm{C}\end{array}$ & $\begin{array}{c}\text { Exothermic } \\
\text { peak } /{ }^{\circ} \mathrm{C}\end{array}$ & $\begin{array}{c}\text { Endothermic } \\
\text { peak } /{ }^{\circ} \mathrm{C}\end{array}$ & $\begin{array}{c}\text { Exothermic } \\
\text { peak } /{ }^{\circ} \mathrm{C}\end{array}$ & $\begin{array}{c}\text { Endothermic } \\
\text { peak } /{ }^{\circ} \mathrm{C}\end{array}$ & $\begin{array}{c}\text { Exothermic } \\
\text { peak } /{ }^{\circ} \mathrm{C}\end{array}$ \\
\hline Waterbath & $32.9-216.4$ & 855.4 & $39.6-205.2$ & 861.6 & $34.6-218.1$ & 859.3 \\
Microwave & $42.7-197.4$ & 852.3 & $31.7-186.2$ & 853.5 & $34.7-212.3$ & 883.2 \\
\hline
\end{tabular}



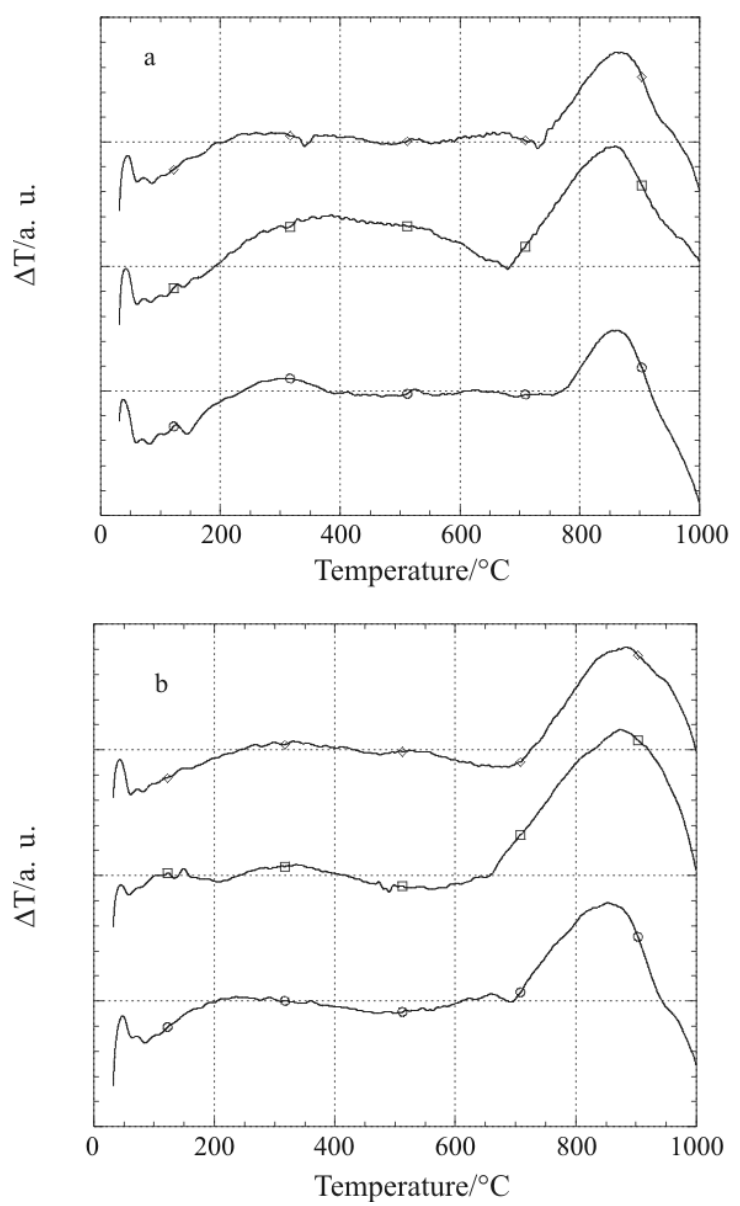

Fig. 5 DTA of the Ag-exchanged minerals exchanged in $\mathrm{a}$ - waterbath, $\mathrm{b}$ - microwave (top to bottom: 80,60 and $40^{\circ} \mathrm{C}$ of exchange)

The smooth and continuous on TG curves of Ag-exchanged clinoptilolite rich minerals show that no structural changes were obtained upon dehydration. Total percent mass losses of the Ag exchanged mineral both in waterbath and microwave were found around $9.85 \%$. TG results showed that, the exchange with Ag does not change the mass loss amounts. Additionally, it has been concluded that treatment method and exchangeable cation content do not have significant effect on the mass $\operatorname{loss} \%$ as indicated in Table 6. These findings are in good agreement with literature. For example, Rehakova et al., 1997, studied the thermal behaviour of zeolitic products Ag-ZSM5 and K-ZSM5/AgI in which their structure remained the same upon heating (up to $1050^{\circ} \mathrm{C}$ ) only they revealed water molecules but in a reduced amount in comparison with the original zeolite Na-ZSM5 [21]. In the following years, Cuvanova et al., 2006, studied the thermochemical properties of these two-kind composite materials. They observed no changes of the zeolitic mineral dimensions that were sintered at temperature $500^{\circ} \mathrm{C}$ for $20 \mathrm{~h} \mathrm{[22]}$.
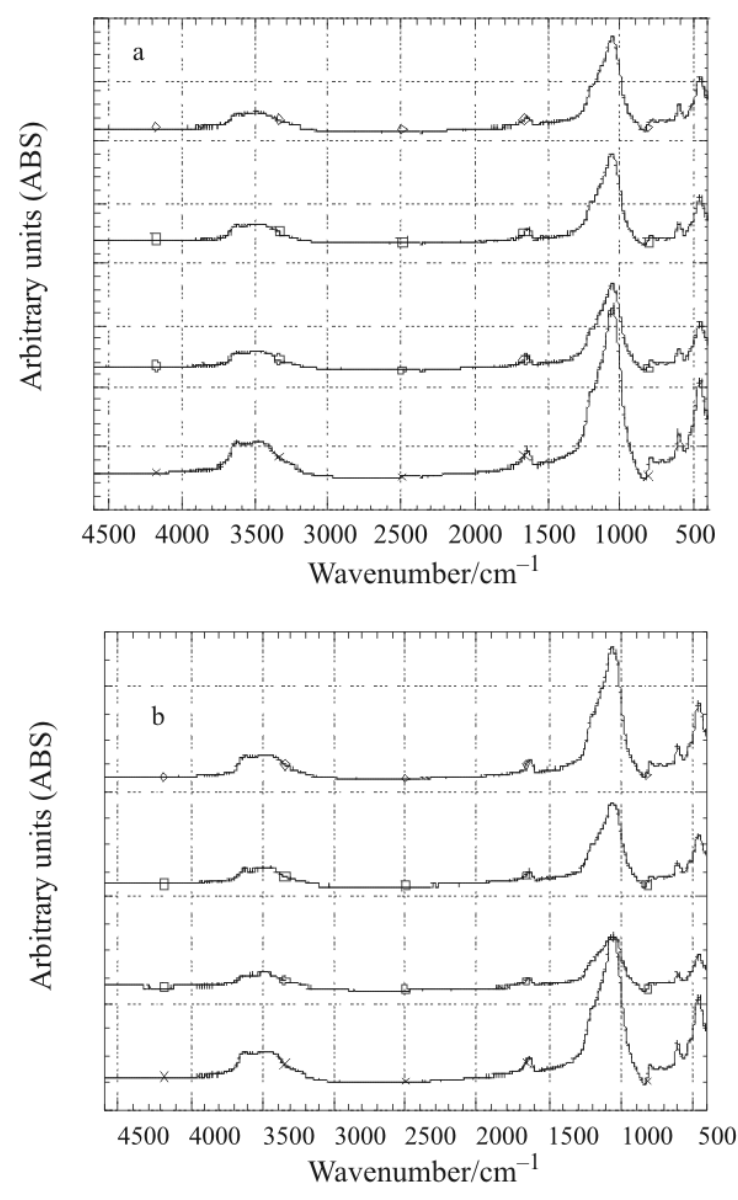

Fig. 6 FTIR of the Ag-exchanged minerals in comparison with Na-form mineral exchanged in a - waterbath, b - microwave (top to bottom: 80,60 and $40^{\circ} \mathrm{C}$ of exchange and $\mathrm{Na}$-form clinoptilolite rich mineral)

DTA patterns of the Ag-form clinoptilolite rich mineral at different temperatures of waterbath and microwave exchange in comparison with Na-form of the mineral are given in Figs 5a and b, respectively showing the thermal decomposition of the minerals. Their data are summarized in Table 6 .

DTA patterns of the Ag-exchanged minerals showed that they were still thermally stable up to higher temperatures. Their structures start to collapse around $850^{\circ} \mathrm{C}$. Compared to parent mineral the decomposition temperatures of the $\mathrm{Ag}$ exchanged minerals shifted to lower temperatures mainly caused by the difference in cation composition within the minerals. However, the observed decrease in the decomposition temperatures of the $\mathrm{Ag}$ exchanged minerals does not affect their potential use for different applications.

FTIR patterns of the Ag-form clinoptilolite rich mineral at different temperatures of waterbath and microwave exchange in comparison with $\mathrm{Na}$-form of the mineral are given in Figs 6a and $b$.

As recalled in the 'Introduction part', FTIR spectra of clinoptilolite classified by Breck [6] are 
observed for all the Ag-exchanged and Na-form minerals supporting that the structure of the minerals did not change with the Ag exchange and the exchange method applied.

\section{Conclusions}

The clinoptilolite rich mineral studied throughout the study has JSPDS card 83-1261 belonging to clinoptilolite having some extra peaks corresponding to heulandite (80-0465) and additionally, mordenite, calcite and quartz were present. The typical clinoptilolite crystals were clearly seen on the parent mineral SEM.

Thermal analyses done with in the range of room temperature to $1000^{\circ} \mathrm{C}$ at 2 and $10^{\circ} \mathrm{C} \mathrm{min}^{-1}$ of heating rates showed that, particle size and heating rate do not have significant effect on the dehydration behavior and structural breakdown temperature of the parent mineral. The XRD, SEM and FTIR analyses showed that the minerals exchanged in waterbath and microwave did not undergo any structural changes. However, the decomposition temperatures of the Ag-exchanged minerals were decreased indicating that they were less thermally stable compared to parent mineral, which does not affect their use for possible applications.

\section{References}

1 F. Ç. Özkan and S.Ülkü, Ambalaj Kongresi ve Yan Sanayi Kongresi ve Sergisi Izmir, (1997) 227.

2 G. E. Christidis, D. Moraetis, E. Keheyan, M. Akhalbedashvilli, N. Kekelidze, R. Gevorkyan, H. Yeritsyan and H. Sargsyan, Appl. Clay Sci., 24 (2003) 79.

3 T. Perraki and A. Orfanoudaki, Appl. Clay Sci., 25 (2004) 9.

4 G. Cruciani, J. Phys. Chem. Solids, 67 (2006) 1973.
5 B. Concepcion-Rosabal, G. Rodrigues-Fuentes, N. Bogdanchikova, P. Bosch, M. Avalos and V. H. Lara, Micropor. Mesopor. Mater., 86 (2005) 249.

6 D. W. Breck, Zeolite Molecular Sieve; Structure, Chemistry and Use, John Wiley and Sons, New York 1974.

7 V. N. Smirenskaya and V. I. Vereshchagin, Glass Ceram., 59 (2002) 28.

8 F. Esenli and I. Kumbasar, Zeolites Related Micropor. Mater.: State of The Art, 64 (1994) 645.

9 E. Chmielewská, L. Sabová and K. Jesenák, J. Therm. Anal. Cal., 92 (2008) 567.

10 A. D. Vujaković, M. A. Djuričić and M. R. Tomaević-Čanović, J. Therm. Anal. Cal., 63 (2001) 161.

11 D. Misshra, Stud. Surf. Sci. Catal., 154 (2004).

12 M. Afzal, G. Yasmeen, M. Saleem, P. K. Butt, A. K. Khattak and J.Afzal1, J. Therm. Anal. Cal., $62(2000) 72$.

13 M. Afzal, G. Yasmeen, M. Saleem, P. K. Butt, A. K. Khattak and J. Afzalı, J. Therm. Anal. Cal., $62(2000) 277$.

14 N. Petrova, T. Mizota and K. Fujiwara, J. Therm. Anal. Cal., 64 (2001) 157.

15 A. Arcoya, J. A. Gonzalez, N. Travieso and X. L. Ve Seona, Miner. Soc., 29 (1993) 123.

16 Ö. Çağlar Duvarcı, Y. Akdeniz, F. Özmıhçı, S. Ülkü, D. Balköse and M. Çiftçioğlu, Ceram. Int., 33 (2006) 795.

17 B. Erdoğan, M. Sakızcı and E. Yörükoğulları, Appl. Surf. Sci., 254 (2008) 2450.

18 P. Costaldi, L. Santona, C. Coza, V. Giuliano, C. Abbruzzese, V. Nastro and P. Melis, J. Mol. Struct., 734 (2005) 99.

19 M. Rivera-Garza, M. T. Olguin, I. Garcia-Sosa, D. Alcantara and G. Rodriguez-Fuentes, Micropor. Mesopor. Mater., 39 (2000) 431.

20 R.-M. Woods and M. E. Gunter, Am. Mineral., 86 (2001) 424.

21 M. Rehakova, A. Sopkova, K. Jesenak and V. S. Fajnor, J. Therm. Anal. Cal., 50 (1997) 505.

22 S. Cuvanová, M. Reháková, Z. Bastl, A. Pollicino, S. Nagyová and V. Fajnor, J. Therm. Anal. Cal., 84 (2006) 721.

DOI: $10.1007 / \mathrm{s} 10973-008-9358-7$ 